\title{
FEMININO E PSICANÁLISE: UM ESTUDO SOBRE A LITERATURA PSICANALÍTICA ${ }^{1}$
}

\author{
Gisele Cristiane Senne de Moraes \\ Nelson Ernesto Coelho Junior
}

\begin{abstract}
RESUMO. Apresentaremos os resultados de uma pesquisa sobre mulher e feminino na literatura psicanalítica realizada a partir da análise de artigos publicados em dois períodos: no auge do feminismo e na atualidade. Ao longo da pesquisa, verificamos que os artigos escritos no auge do feminismo permaneciam apegados à lógica fálica (do ter ou não ter) no tocante ao desenvolvimento psíquico da mulher, e que os artigos da atualidade apresentaram uma maior multiplicidade de aspectos, o que inclui questões envolvendo o complexo de castração, com sua implícita lógica fálica. $\mathrm{O}$ discurso do auge do feminismo, ao buscar estabelecer um lugar para a mulher diferente do lugar de negativo do homem, mostra a relevância atribuída, então, à lógica binária fálica, enquanto o discurso dos textos mais atuais busca o estabelecimento de um campo próprio e de uma positividade para a mulher na psicanálise.
\end{abstract}

Palavras-chave: Psicanálise; mulher; feminismo.

\section{FEMALE GENDER AND PSYCHOANALYSIS: A STUDY ON PSYCHOANALYTICAL LITERATURE}

\begin{abstract}
This work will introduce the results obtained by a research of woman and female gender representation in psychoanalytical literature, which was made by analyzing articles published either during the feminist movement's peak or in the present time. The research allowed us to verify that articles written during the feminist movement's peak were attached to the phallic logic (of having or not having) regarding women's psychic development. Recent articles show a wider range of aspects, which also include the castration complex issues with its implicit phallic logic. The speech regarding the female gender during the feminist movement's peak shows the importance of the phallic-binary logic, by trying to establish a place to women different than the negative of men, while the same speech in recent times is more focused in setting up a specific field for women in psychoanalysis.
\end{abstract}

Key words: Psychoanalysis; woman; feminism.

\section{FEMENINO Y PSICOANÁLISIS: UN ESTUDIO SOBRE LA LITERATURA PSICOANALÍTICA}

\begin{abstract}
RESUMEN. Presentaremos los resultados de una pesquisa acerca de las representaciones del la mujer en la literatura psicoanalítica, realizada a partir del análisis de los artículos publicados en dos períodos: auge del feminismo y la actualidad. Verificamos que los artículos escritos en el auge del feminismo han permanecido relativos a la lógica fálica (del tener o no tener) y los artículos de la actualidad presentaran una mayor multiplicidad de aspectos, que incluyen también las cuestiones del complejo de la castración, cuya lógica implícita es fálica. El discurso del auge del feminismo, al buscar establecer un lugar distinto del lugar del negativo del hombre, pone en evidencia la relevancia atribuida a la lógica binaria fálica, en cuanto el discurso de los textos más actuales busca el establecimiento de un campo propio y de una efectividad para la mujer en el psicoanálisis.
\end{abstract}

Palabras-clave: Psicoanálisis; mujer; feminismo.

O presente texto relatará os resultados de uma pesquisa (financiada pela FAPESP, processo 05/57539-2) sobre os discursos da psicanálise a respeito da mulher e do feminino realizada a partir de uma revisão bibliográfica de artigos psicanalíticos publicados em dois períodos distintos: o do auge do

1 Apoio: FAPESP.

Psicóloga, psicanalista e aspirante a membro no Departamento de Psicanálise do Instituto Sedes Sapientiae.

\# Doutor em psicologia clínica. Professor, pesquisador e orientador dos cursos de graduação e pós-graduação do Instituto de Psicologia da USP. 
feminismo e o da atualidade. Para Mitchel (1979), Freud permanecia como o inimigo da maior parte do feminismo, à época da publicação de seu livro. Em 1979 o feminismo já havia se estabelecido como um importante movimento social; a análise da autora empreendida sobre a psicanálise é contemporânea ao movimento e certamente não pode ser isolada dele. Porém Mitchel seguiu em direção contrária à crítica generalizada a Freud, resgatando-o em sua importância para o próprio movimento, como veremos aqui. Mais de vinte anos se passaram após o auge e consolidação do movimento social, o que possibilita uma análise mais distanciada do discurso da psicanálise durante o auge do feminismo e após. A psicanálise é um campo de conhecimento que possui discurso próprio, conceituações que a caracterizam como tal e independem da sociedade em questão (como a existência do inconsciente no psiquismo, por exemplo), mas pensá-la e olhá-la sem excluir as particularidades da sociedade proporciona-lhe maior riqueza. Assim, o presente artigo busca trazer um olhar comparativo entre os discursos psicanalíticos sobre a mulher no auge do feminismo e cerca de vinte anos após o auge do movimento. Nos textos do auge do feminismo encontramos um esforço em mostrar a mulher como diferente do negativo do homem, o que, em nossa opinião, mantém o homem como referência e o discurso fálico como central. Já nos textos da atualidade, verificamos um discurso que, predominantemente, preocupava-se em tecer uma positividade sobre a mulher e em lhe estabelecer um estatuto próprio, o que propiciou maior multiplicidade ao campo.

\section{MÉTODO}

Para realizar a revisão bibliográfica foram analisados trinta artigos extraídos de seis periódicos psicanalíticos nos períodos de 1965 a 1975 e 1995 a 2004, que representam o auge do feminismo e a atualidade, respectivamente. Definimos como foco da pesquisa os artigos que atribuíam ênfase à constituição do psiquismo da mulher ${ }^{2}$ e comparamos os textos

2 Os periódicos selecionados foram: The International Journal of Psycho-analysis, The Psychoanalytical Quarterly, The American Journal of Psychoanalysis, Revista Brasileira de Psicanálise, Revista Percurso e Revista Tempo Psicanalítico. Para a atualidade, selecionamos os dez anos anteriores à data de solicitação da bolsa à FAPESP e para o auge do feminismo, um período intermediário entre as décadas de sessenta e setenta do século passado. Finalmente, classificamos os textos em três categorias de acordo com a ênfase em: (i) constituição do analisados nos dois períodos selecionados. Iremos, a seguir, relembrar brevemente as concepções freudianas sobre a mulher, para depois apresentarmos os resultados encontrados na pesquisa.

\section{FREUD E A MULHER}

Lembremos que Freud dedicou poucos textos exclusivamente ao psiquismo da mulher e que suas concepções geraram polêmicas desde as primeiras publicações exclusivas sobre o tema. Lembremos também que entre os mais relevantes escritos prépsicanalíticos do autor estão os "Estudos sobre a Histeria" (1895/1996), baseados em atendimentos clínicos a mulheres, e que tais estudos buscavam compreender o psiquismo das histéricas tratadas por Freud e Breuer; mas Freud pareceu evitar abordar a questão específica do psiquismo da mulher por um longo período, por dizer-se ainda desconhecedor do universo feminino, sobre o qual só começou a expressar suas visões mais incisivamente a partir da década de trinta do século passado.

No entanto, nos artigos "A Dissolução do Complexo de Édipo" (Freud, 1924/1976) e "Algumas Consequências Psíquicas da Distinção Anatômica Entre os Sexos" (Freud, 1925/1976), o autor já esboçou suas ideias sobre o psiquismo feminino, porém ainda com incertezas. No artigo de 1924 escreveu sobre a importância do medo de castração para que o menino internalize (introjete e identifiquese com a figura paterna) os valores sociais. Ele abandonaria seus objetos de amor parental em nome do narcisismo pela parte ameaçada do corpo, ou seja, em prol da manutenção de seu órgão sexual. A menina, por sua vez, já entraria castrada no complexo de Édipo e o que provocaria a instauração de seu superego seria a angústia advinda da perda do amor parental. Ao perceber que não possui um pênis, por uma equação simbólica, igualaria o pênis a um bebê, passando a desejar ter um bebê com seu pai. Como este desejo jamais se realiza, aos poucos ela o abandonaria, mas reteria, em seu inconsciente, tanto o desejo original (ter um pênis) quanto o deslocado (ter um bebê), ambos necessários para que futuramente assuma seu papel de mulher. A menina já entraria castrada no complexo de Édipo porque acredita que chegou a possuir um pênis (disposição masculina inicial), em função de o clitóris funcionar como o órgão masculino (Freud, 1924/1976, p. 222-223):

psiquismo da mulher; (ii) atributos da feminilidade; e (iii) história da psicanálise da mulher. 
O clitóris na menina inicialmente comportase exatamente como um pênis, porém, quando ela efetua uma comparação com um companheiro de brinquedos do outro sexo, percebe que 'se saiu mal' e sente isso como uma injustiça feita a ela e como fundamento para inferioridade. Por algum tempo ainda, consola-se com a expectativa de que mais tarde, quando ficar mais velha, adquirirá um apêndice tão grande quanto o do menino... Uma criança do sexo feminino, contudo, não entende sua falta de pênis como sendo um caráter sexual; explica-a presumindo que, em alguma época anterior, possuíra um órgão igualmente grande e depois perdera-o por castração. Ela parece não estender essa inferência de si própria para outras mulheres adultas, e sim, inteiramente segundo as linhas da fase fálica, encará-las como possuindo grandes e completos órgãos genitais — isto é, masculinos. Dá-se assim a diferença essencial de que a menina aceita a castração como um fato consumado, ao passo que o menino teme a possibilidade de sua ocorrência.

No artigo de 1925, segundo comentário do editor inglês (Freud, 1925,1976), Freud já teria exposto todos os pontos cruciais de sua teoria sobre o desenvolvimento psíquico da mulher: (i) a mãe como primeiro objeto de amor da menina; (ii) os destinos que a menina pode ter ao se deparar com sua castração e o complexo de masculinidade; (iii) o ciúme como uma característica inerente ao feminino; (iv) as origens da ideia de masoquismo também como um traço do feminino; (v) o abandono do prazer clitoridiano em direção ao prazer vaginal, em paralelo ao abandono da mãe como objeto amoroso em direção ao pai; (vi) o menor senso de justiça da mulher em relação ao homem; entre outros.

Como dissemos, os artigos dedicados especialmente ao psiquismo da mulher foram escritos tardiamente na obra freudiana, e são dois textos da década de trinta. Em "Sexualidade Feminina" (Freud, 1931/1974, p. 260-261), o autor explicou suas dificuldades em compreender o psiquismo feminino:

Tudo na esfera dessa primeira ligação com a mãe me parecia tão difícil de apreender nas análises - tão esmaecido pelo tempo e tão obscuro e quase impossível de revivificar que era como se houvesse sucumbido a uma repressão especialmente inexorável.

Nesse artigo Freud não se limitou a se aprofundar sobre o tema do feminino, tendo elaborado proposições sobre o que denominou de civilização mino-miceniana no desenvolvimento infantil, ou seja, a fase pré-edipiana. As dificuldades de compreensão do psiquismo feminino adviriam da importância que este período representa para o desenvolvimento psíquico da mulher. Aqui está em jogo a relevância da ligação da mãe com sua filha, que, por sua vez, está se constituindo como mulher. Desta forma, os obstáculos encontrados pelo autor no entendimento sobre o feminino resultariam da barreira (recalque) sempre tão presente na investigação desta fase inicial da vida. Antes de a menina entrar no complexo de Édipo positivo - tendo o pai como objeto de amor e a mãe como rival - passaria por um complexo de Édipo negativo, no qual as relações de amor e de ódio com as figuras parentais estariam invertidas. Para a menina, inicialmente, o pai seria um rival ao amor da mãe.

Em "Novas Conferências Introdutórias Sobre Psicanálise: Feminilidade" (Freud 1933/1976), Freud discorreu sobre aspectos do desenvolvimento da mulher já comentados antes, como a disposição masculina inicial; a necessidade de deslocamento da zona erógena clitoridiana para a vagina; a importância da vinculação inicial com a mãe; a hostilidade com a mãe na fase edipiana; além de ter enfatizado os aspectos do ciúme e da inveja como mais fortes na mulher que no homem: "Não é que eu pense estarem essas características ausentes nos homens, ou julgue que elas não tenham nas mulheres outras raízes além da inveja do pênis; estou inclinado, no entanto, a atribuir quantidade maior nas mulheres a essa influência." (Freud, 1933/1976, p. 154). Teorizou também sobre características inerentes ao desenvolvimento normal da mulher, como o masoquismo - pela supressão da agressividade que lhe é socialmente imposta. Finalmente, atribuiu características psíquicas peculiares à feminilidade adulta: a inferioridade, a necessidade da mulher mais de ser amada do que de amar, a vaidade e a vergonha. Todos estas características ocorreriam em função dos atributos anatômicos da mulher, de uma maneira ou de outra. O trecho a seguir expõe a opinião de Freud (1933/1976, p. 162) com relação aos atributos citados na frase anterior:

Assim, atribuímos à feminilidade maior
quantidade de narcisismo, que também afeta
a escolha objetal da mulher, de modo que,
para ela, ser amada é uma necessidade mais
forte que amar. A inveja do pênis tem em
parte, como efeito, também a vaidade física
das mulheres, de vez que elas não podem
fugir à necessidade de valorizar seus
encantos, do modo mais evidente, como uma
tardia compensação por sua inferioridade
sexual original. A vergonha, considerada 
uma característica feminina par excellence, contudo, mais do que se poderia supor, sendo uma questão de convenção, tem, assim acreditamos, como finalidade a ocultação da deficiência genital.

Finalmente, nos textos "Análise Terminável e Interminável" (Freud, 1937/1975) e "Esboço de Psicanálise" (Freud, 1940/1975) também encontramos trechos sobre o psiquismo da mulher. No primeiro, Freud refere-se à inveja do pênis e à retenção desta no inconsciente como importante fator de resistência ao trabalho terapêutico em mulheres. Assim, "esse desejo é fonte de irrupções de grave depressão nela [mulher], devido à convicção interna de que a análise não lhe será útil e de que nada pode ser feito para ajudá-la" (Freud, 1937/1975, p. 286-287) e mais adiante (Freud, 1937/1975, p. 287):

A coisa decisiva permanece sendo que a resistência impede a ocorrência de qualquer mudança - tudo fica como era. Frequentemente temos a impressão de que o desejo de um pênis e o protesto masculino penetraram através de todos os estratos psicológicos e alcançaram o fundo, e que, assim, nossas atividades encontram um fim.

O fim, para Freud, seria uma barreira biológica, cuja expressão na mulher seria a inveja do pênis e no homem, a atitude feminina. Por último, em "Esboço de Psicanálise" (Freud, 1940/1975), escreveu novamente considerações sobre a mulher já trabalhadas em textos anteriores e reforçou a ideia de que a inveja do pênis poderia ser uma das estruturas mentais menos acessíveis na mulher.

\section{UM FREUD CRIATIVO COM RELAÇÃO AO FEMININO}

Embora possa soar estranho fazer uma referência à potência criativa de Freud num texto sobre psicanálise e mulher, em especial depois do que comentamos sobre suas proposições, é pertinente fazêlo. Freud foi um autor que insistiu em permanecer numa fronteira muito tênue entre conceitos. No tocante à diferenciação sexual, por exemplo, suas concepções se apoiam na biologia e na anatomia: homens e mulheres são diferentes, seus destinos são, consequentemente, distintos. Ao mesmo tempo, numa determinada idade, a menina - mesmo com um corpo diferente do corpo do menino - acredita ter sido possuidora de um pênis, portanto, igual a um menino. Freud, sem nomeá-lo, recorreu à neurofisiologia das sensações para responder a este aparente paradoxo: o clitóris funciona como um pênis, pois as sensações que proporciona são similares às do pênis; mas, em nossa compreensão, este é um dos momentos em que Freud se coloca numa outra fronteira, aquela entre o anatômico e a fantasia. É na fantasia da menina, numa fantasia apoiada em suas sensações corporais, que está o conceito de monismo fálico (ou disposição masculina inicial). Certo ou errado, temos que reconhecer que Freud encontrou uma solução criativa, uma manobra bastante engenhosa que lhe possibilitou manter a questão da castração como crucial ao psiquismo. Tal questão, se apoiada exclusivamente na anatomia, não faria o menor sentido para a mulher, pois não há como sofrer pela perda do que nunca se teve. Pode-se sofrer pela falta, mas não pela perda do que não se teve.

Poderíamos parar por aí, mas há mais material criativo. No texto "Sexualidade Feminina" (Freud, 1931/1974) Freud destacou a importância das primeiras relações objetais da mulher, na relação mãefilha. Ao dizer isto, o autor não apenas encontrou uma razão para as dificuldades com as quais se deparara em questões envolvendo o psiquismo feminino, mas também abriu caminho para se pensar a característica identificatória desta relação, o que, como veremos, é um dos aspectos da multiplicidade que encontramos nas produções da atualidade. Mesmo antes, Freud também abriu caminho para teorizações específicas sobre a mulher como positividade, quando afirmou que a angústia nela predominante para a instauração do superego é a advinda da perda do amor parental. Mitchel (1979) vai um pouco além e sugere que Freud buscou dar um estatuto próprio à mulher, ao enfatizar as diferenças pelas quais meninas e meninos passam em seu desenvolvimento psíquico. Para essa autora, as ideias freudianas teriam sido essenciais ao desenvolvimento posterior do movimento feminista, por terem dado um lugar próprio à mulher e, também, pelo desconforto que geraram tanto no meio psicanalítico quanto na sociedade ocidental.

\section{O INTOCÁVEL LUGAR DA CASTRAÇÃO NA PSICANÁLISE}

Como dissemos, a solução criativa de Freud de posicionar a anatomia como destino, no sentido de objetivo a ser atingido, possibilitou a manutenção da castração como central à teoria freudiana. $\mathrm{O}$ complexo de castração, que se centra na fantasia de castração, apresenta manifestações distintas em meninos e meninas. No menino, manifesta-se como angústia de castração, e na menina, aparece como o dano sofrido 
que ela nega ou tenta compensar, dano cuja percepção resultaria na inveja do pênis e no sentimento de inferioridade, por exemplo.

Façamos aqui um exercício de imaginação. Pensemos numa teoria psicanalítica que não tenha se fundado em tanta ênfase atribuída ao tema da castração, seja como angústia seja como sentimento de dano. O que promoveria, então, a instauração do superego? Talvez o outro medo sugerido por Freud, o da perda do amor parental, em especial o da mãe. Neste caso, teríamos que antecipar este momento crucial à vida psíquica, quando os valores morais e sociais são absorvidos e incorporados pelo psiquismo. Outro efeito bastante razoável de se imaginar seria certo obscurecimento do papel do pai no desenvolvimento psíquico da criança. Se seu papel deixa de ser o de produtor do temor pela perda do órgão, qual passaria a ser? Talvez seu papel passasse a ser o de responsável pela separação entre mãe e bebê e, talvez, o temor que existisse com relação a ele seria apenas o medo de perder também o amor do pai.

Até aqui, tudo o que foi proposto no parágrafo anterior, neste exercício de especulação, pode ser encontrado nas ideias do próprio Freud - ou nas de Klein e de outros autores ingleses, por exemplo; no entanto, mesmo os autores ingleses, que aparentemente não enfatizam tanto a questão da castração, utilizam a expressão "fase fálica" para denominar uma fase do desenvolvimento psíquico da criança. Ora, na digressão que fizemos - imaginando a diminuição da importância da castração na psicanálise - talvez pudéssemos imaginar que o órgão masculino não se estabelecesse como parâmetro de positividade e, neste caso, talvez não houvesse uma fase do desenvolvimento psíquico chamada de fálica. Esta fase do desenvolvimento psíquico poderia ser denominada genital infantil, por exemplo, já que esta é a parte do corpo (de crianças de ambos os sexos) que parece organizar suas vidas psicossexuais de então, além de ser nesta fase que as diferenças de gênero são percebidas.

$\mathrm{O}$ que queremos com o caminho percorrido neste item é propor que, mesmo a psicanálise que mais se distanciou do conflito edípico, tal como Freud o pensou - a qual intimamente se liga à questão da castração (Laplanche \& Pontalis, 2001) - herdou algo que poderia ser denominado de falocentrismo originário da psicanálise, enraizado de forma tão entranhada no meio que se mantém na nomenclatura de diferentes correntes psicanalíticas. Tal falocentrismo, no entanto, não parece ser apenas resultado da cultura preponderante na sociedade europeia que Freud conheceu. É a própria relevância do complexo de castração que o sustenta. A castração permanece como sendo um conceito central ao campo.

Lembremos que a importância atribuída por Freud à questão da castração - seja na sua manifestação em mulheres seja em homens - fundamentou-se em suas observações clínicas. Assim, em primeiro lugar, a questão parece de fato ser central às pessoas do sexo masculino, na sua expressão de angústia, o que a coloca como fundamental para aproximadamente metade da população mundial. Não é pouco. Adicionalmente, como veremos adiante no texto, a inveja do pênis, considerado um dos efeitos clínicos do complexo de castração (Laplanche \& Pontalis, 2001), parece ser um fenômeno de fato observável em meninas. Ora, há algo de muito visível no corpo masculino, algo que a menina não possui. Dentro da lógica da falta, é bastante razoável imaginar a menininha se dando conta da existência deste algo visível e se questionando quanto aos motivos de não tê-lo.

Laplanche e Pontalis levantam a questão: como pode uma menina se sentir ameaçada pela "perda" de um órgão que jamais possuiu? Os autores sugerem que a "presença [do complexo de castração] quase invariável em todos os seres humanos" (Laplanche \& Pontalis, 2001, p.74) advém do fato de o complexo ter deixado de se basear exclusivamente na literalidade da angústia de castração e ter, assim, assumido diferentes direções na psicanálise. O complexo de castração passou a equivaler a perdas e separações que a criança enfrenta ao longo de seu desenvolvimento, e não apenas à perda do pênis. Para os autores, portanto, a castração permanece quase universalmente observável ao se aproximar do caráter mais fantasístico das perdas ou interdições em geral. Neste sentido, a manutenção da posição privilegiada que a castração ocupa na psicanálise teria resultado de um distanciamento em relação ao pênis. Destarte, o afastamento em relação ao apoio corporal defendido por Freud pode ter permitido a sobrevivência da relevância do complexo de castração na psicanálise.

\section{A NEGAÇÃO DA MULHER COMO NEGATIVIDADE}

Inserimos um item denominado "O intocável lugar da castração na psicanálise" porque o complexo envolvendo fantasias de castração pareceu-nos um bom organizador das diferenças encontradas nos textos entre o auge do feminismo e a atualidade. A castração entendida como a lógica fálica do ter ou não ter é uma lógica que abarca dois valores: o sim ou o 
não; a presença ou a ausência; o um ou o zero. É uma lógica binária, portanto.

Nos textos analisados do período do auge do movimento feminista, a lógica binária fálica permanece como o principal norteador dos discursos. Diversos artigos buscavam negar que a mulher se encaixasse no eixo negativo da lógica binária (no zero ou no não ter). Lembremos que a castração da mulher, em Freud, existe pelo fato de o clitóris funcionar como um pênis na fantasia da menina. Lembremos também que a aceitação da castração vem acompanhada dos abandonos do prazer clitoridiano e da mãe como objeto amoroso, o duplo movimento necessário para que o destino da mulher seja alcançado. A disposição masculina inicial da mulher (ou monismo fálico) é o ponto inicial da lógica fálica no pensamento freudiano (e aqui nos limitamos a Freud). Assim, não é à toa que o principal argumento usado para fundamentar a inconsistência do posicionamento da mulher no eixo negativo da lógica da castração foi justamente este ponto. Se a menina não possui a fantasia de ter um pênis no início da sua vida, não haveria razão para sofrer por sua perda quando se percebesse sem um, como já comentamos. Se a fantasia de possuir um pênis deixa de existir, a castração (e sua subsequente lógica) tenderia a se esvaziar, segundo o pensamento freudiano.

Não obstante, como dissemos, o grande volume de textos que se posicionam contra o monismo fálico, no auge do movimento feminista, expressa a relevância que a lógica fálica possuía nesse período. É o que estamos aqui denominando de negação da negatividade da mulher. Vale comentar que o único artigo de toda a pesquisa que expressamente concorda com o monismo fálico foi publicado no auge do movimento feminista, o que também sugere sua relevância para o período.

Os artigos que se posicionam contrariamente ao monismo fálico, por sua vez, seguem dois caminhos distintos de fundamentação. Recorrem à biologia ou à identidade de gênero como uma construção social. A última argumentação está presente nos artigos de Robert Stoller, uma referência importante nos artigos da contemporaneidade. Stoller desenvolveu o conceito de feminilidade primária, que seria uma espécie de certeza de pertencer ao gênero feminino, em função da certeza dos pais em relação ao gênero da filha. $\mathrm{O}$ "primário" da expressão stolleriana contradiz justamente o argumento freudiano do monismo fálico, pois a feminilidade é primária por não ser uma defesa construída a partir da percepção da ausência do pênis. $\mathrm{O}$ autor escreve:
Há boa razão para questionar a afirmação sobre a mulher de que 'Sua vida sexual é dividida em duas fases, na qual a primeira tem o caráter masculino e somente a segunda é especificamente feminina'. Na verdade, uma importante proposta deste artigo é dar suporte àqueles que acreditam que Freud pode ter distorcido toda a sua descrição sobre o desenvolvimento da "sexualidade" em meninos e meninas, por sua insistência em começar a história (sob certos aspectos) somente após a fase fálica... há evidências de que o que ele considera a primeira etapa do desenvolvimento de gênero numa menina é de fato etapa secundária... (Stoller, 1968, p. 43), [tradução nossa]. ${ }^{3}$

Embora Stoller faça críticas a Freud com relação à disposição masculina inicial, no mesmo artigo ele procura, no texto freudiano, indicações que sustentem que Freud teria, implicitamente, percebido a existência de uma fase anterior do desenvolvimento da menina, na qual ela se entenderia como pertencente ao gênero feminino. Seu argumento baseia-se numa frase em que Freud se refere a "quando" a menina descobre sua deficiência (por não possuir um pênis). Para Stoller, a palavra "quando" indicaria que houve um antes, ou seja, uma época em que a menina não se percebia deficiente, na qual a feminilidade não era depreciada.

Já no vértice biológico, para sustentação da posição contrária ao monismo fálico, há artigos que enfocam a construção das primeiras simbolizações a partir de percepções corporais da menina, num corpo feminino. Manhães (1975, p. 434), por exemplo, escreve: "Tentar conhecer a mulher como um não homem é partir da negação da realidade". A realidade da mulher é seu corpo. Assim, os artigos organizados no vértice biológico defendem a importância de percepções (conscientes ou inconscientes) da existência do órgão feminino (essencialmente, a vagina) para propor que a mulher não é negatividade em relação ao homem.

\footnotetext{
There is good reason to question Freud's remark about women: 'Their sexual life is regularly divided into two phases, of which the first has a masculine character, while only the second is specifically feminine'. In fact, an important purpose of this paper is to support those who believe that Freud may have distorted his whole description of the development of 'sexuality' in both boys and girls by his insistence on beginning the story (in certain regards) only after the onset of the phallic phase... there is evidence that what he considers the first phase of gender development in a little girl is in fact a secondary phase... (Stoller, 1968, p. 43).
} 
Finalmente, ainda dentro do prisma biológico, encontramos um interessante artigo escrito por André Green, no qual o autor recorre, implicitamente, à lógica piagetiana: crianças conhecem o mundo a partir de sua própria noção de eu - um eu que já é do gênero feminino ou masculino, como notamos no trecho a seguir:

O inconsciente parece não levar em conta a realidade anatômica, dado que crianças de ambos os sexos assumem que há somente um gênero: meninos pensam que todos os humanos possuem pênis, enquanto meninas acreditam que todos são construídos como elas mesmas (Green, 1972, p. 210), [tradução nossa]. ${ }^{4}$

\section{O ANGUSTIANTE UNIVERSO DO MÚLTIPLO, DO DIFUSO E DO IMPRECISO}

Multiplicidade é o que encontramos nos textos da contemporaneidade. Apresentar e falar desta multiplicidade implica entrar num mundo muito mais diverso e impreciso que a lógica fálica permite. $\mathrm{O}$ múltiplo pode ser angustiante, por apresentar uma diversidade que não permite reducionismos. Nas próximas páginas abordaremos alguns dos principais aspectos que encontramos neste campo fértil de produções sobre a mulher na atualidade, o que pode gerar no leitor também certa angústia. Não há como falar das produções atuais sem entrarmos em sua diversidade.

Antes de tudo tentaremos compreender por que a castração, tal como proposta por Freud, aparece de forma mais indireta nos artigos da atualidade. $\mathrm{O}$ tema parece ter deixado, em algum momento, de ser um ponto central para a questão da mulher na psicanálise. Muitos textos comentam uma coisa ou outra sobre o complexo de castração, mas de forma esparsa. Não nos fica claro, em muitos artigos, se os autores concordam com a existência do fenômeno ou não, apesar de alguns deles se posicionarem contrariamente ao monismo fálico. Há um artigo que defende a existência do complexo sem a premência do monismo fálico, o que é possível na medida em que o conceito se distancia de fantasias envolvendo diretamente o pênis. Aliás, outros fenômenos também se descolam da premência da existência do monismo fálico. É o

4 The unconscious does appear to take no account of anatomical reality, for children of either sex assume that there is only one sex: boys think that all humans have penises and girls think everyone is built like themselves (Green, 1972, p. .210). que observamos com a inveja do pênis, que aparece frequentemente nos artigos dos dois períodos, embora na atualidade a inveja do pênis seja compreendida como uma defesa contra a percepção de incompletude que as diferenças anatômicas produzem nos dois gêneros. Seria um fenômeno relacionado ao desejo de possuir ambos os sexos. Não somos seres completos, não temos tudo. Meninas não têm pênis e invejam coisas de meninos, e estes, por sua vez, não têm atributos de meninas e invejam, consequentemente, coisas de meninas. Encontramos dois artigos que se baseiam em duas pesquisas de observação sobre esta questão, ambas realizadas nos Estados Unidos (Olesker, 1998; Senet, 2004).

O distanciamento entre o complexo de castração e as fantasias que envolvem exclusivamente a castração envolvendo do órgão masculino parece, de certa forma, ter aberto espaço para busca de teorizações sobre o desenvolvimento psíquico específico da mulher. Neste sentido, a mulher como negação da negatividade do homem dá lugar para a entrada de um campo múltiplo, que, curiosamente, parece manter relação com a própria especificidade do corpo de mulher. O que é o órgão genital feminino? Uma composição, uma multiplicidade. Assim, há espaço para o prazer do clitóris e para o prazer vaginal. Há espaço até para a percepção externa do órgão, como sugere a pesquisa realizada por Senet (2004), na qual as partes externas do órgão feminino eram representadas por crianças de ambos os sexos: vulva passa também a ser uma positividade. Há espaço ainda para um questionamento sobre o eclipse dos seios na literatura sobre a mulher (Volich, 1995), uma vez que estes têm historicamente aparecido somente na relação mãe-bebê na psicanálise. Mas os seios possuem um importante papel organizador no desenvolvimento feminino, pois são referências identificatórias para as meninas. Interessante notar que o caráter múltiplo e difuso do órgão feminino já era defendido em dois artigos do auge do movimento feminista. Mas há um salto nas produções da atualidade, na medida em que esta característica idiossincrática do órgão feminino parece impregnar o campo. De certa forma, a própria multiplicidade de conceituações que foram sendo produzidas parece, curiosamente, fazer um retorno a Freud, no sentido em que retoma fantasias apoiadas nas sensações produzidas pelas especificidades do corpo da mulher, já que o campo sexual em Freud, apesar de não se definir pelo biológico, também não o exclui.

Mulheres então passam a ter angústias e mitologias específicas. Notemos que não há nada de muito novo nisto. Melanie Klein, Karen Horney, Lou- 
Salomé, Ernest Jones, para citar somente alguns autores, já haviam escrito sobre angústias e questões específicas do desenvolvimento psíquico das mulheres nas primeiras décadas do século passado. De alguma forma, tais produções perderam força em meio à necessidade de negar Freud por suas ideias aparentemente fálicas sobre a mulher. Poderíamos até pensar na mulher do auge do movimento feminista como uma mulher "fálica", que nega a própria castração! Ironias da história... A mulher que tenta de forma tão tenaz se afirmar como não homem é uma mulher tão "masculinizada" quanto um homem.

Como dissemos, a multiplicidade do campo na atualidade se expressa nas discussões à respeito de temas relacionados especificamente às mulheres, como suas angústias, suas patologias mais características ou mitologias sobre seu desenvolvimento.

Com relação às angústias, encontramos um grande volume de produções que abarcam o tema na contemporaneidade, diferentemente do período anterior analisado na pesquisa. A escassez de artigos sobre o tópico, no auge do movimento feminista, chama atenção, pois muito já havia sido redigido sobre as angústias femininas à época. $\mathrm{Na}$ verdade, apenas um artigo realmente aborda a questão, mas de maneira superficial, recorrendo a Klein e a Horney, como percebemos na seguinte frase: "[as angústias femininas dizem respeito] ao medo retaliatório de depredações de seus órgãos internos" (Manhães, 1975, p. 436). No entanto, este artigo se debruça, na verdade, sobre a angústia que a sociedade falocêntrica demonstra sentir pela capacidade criadora da mulher. Como compreender a pouca relevância dada ao tópico neste período? Encontramos uma alternativa de resposta neste único texto que explora o tema. $\mathrm{Na}$ medida em que a autora se estende mais sobre o horror do homem ao entrar em contato com o feminino, do que sobre as angústias caracteristicamente femininas, empreendendo uma avaliação sobre o medo do homem diante da mulher, são os homens que continuam a ser a referência. Mais uma vez, é a lógica fálica que permanece relevante.

Ainda com relação às angústias das mulheres, alguns textos importantes sobre o assunto foram produzidos nos anos entre os dois períodos que selecionamos para nossa pesquisa, como o artigo de 1990 de Doris Bernstein, intitulado "Female Genial Anxieties, Conflict and Typical Mastery Modes", publicado no periódico The International Journal of Psycho-analysis. Este e outros textos da autora foram usados como referência bibliográfica em diversos dos artigos da contemporaneidade e por isso a citamos aqui.

As angústias consideradas especificamente femininas, nos textos da atualidade, são produzidas na experiência psíquica da menina (ou da mulher) com as peculiaridades de seu corpo. São descritas como medos de difusão, de penetração, de acesso, de ser invadida e agredida pela mãe invasora, de perdas de prazer ou de fertilidade. E o que sustenta tais angústias é a compreensão do órgão feminino como um órgão capaz de produzir sensações múltiplas, difusas e imprecisas; como um órgão difícil de ver e tocar; que não possui um esfíncter e que, desta forma, não possui controle de acesso. A última característica pode predispor mulheres a patologias envolvendo o órgão sexual feminino, como no caso do vaginismo, ou a patologias nas quais as mulheres se identificam com um falo (poderoso) que as protege da intrusão materna, como na anorexia. Encontramos também artigos que falam sobre angústias que não são exclusivamente femininas, mas que produzem efeitos particularmente perigosos nas mulheres, como o medo de simbiose com a mãe, que predisporia a mulher a fobias, paranóia ou hipocondria, pela a ausência de um pênis que permita uma maior diferenciação em relação à mãe. Outros artigos, ainda, falam sobre a forma que a angústia de castração adquire na mulher, como o medo da perda de virgindade ou da mulher não se perceber como um ser completo, quando a menina entra em contato com as diferenças anatômicas.

Finalmente, podemos observar multiplicidade no campo a partir de mitologias ou modelos propostos para o desenvolvimento psíquico da mulher. Encontramos três mitologias distintas. HalberstadtFreud propõe o mito de Electra, Kulish e Holtzman propõem o mito de Perséfone e Birkested-Breen produz o conceito de penis-as-link. O último poderia se estender à compreensão do desenvolvimento psíquico de homens também e representa uma solução híbrida entre ideias kleinianas e lacanianas.

Com o mito de Electra, na forma como retomado por Halberstadt-Freud (1998, 2001), há explicitação da dupla vinculação existente na relação mãe e filha, que sempre se renova ao longo da vida da mulher. A menina não muda de objeto libidinal, para a autora, pois a escolha em direção ao pai (heterossexual) se sobrepõe à escolha em direção à mãe (homossexual). A mãe, no entanto, não é apenas objeto de amor da mulher, mas também de identificação. Daí o duplo vínculo. A cada nova identificação, a mulher tenderia a vivenciar uma regressão. Um bom exemplo seria a situação na qual a mulher tem uma filha e vê reacendida sua identificação com a mãe. Mas, ao 
retornar para a relação com a mãe, voltaria a ser filha. Com isto, Halberstadt-Freud destaca a ambivalência existente na relação da menina com a mãe; uma ambivalência que, para a autora, nunca pode ser totalmente resolvida, pode somente ser mantida em padrões aceitáveis. Ambivalência porque com a regressão, o ódio em direção à mãe edípica seria reeditado. Um ódio advindo tanto da competição pelo amor do pai, quanto pelo desprezo que a mãe demonstra possuir pelo pai amado no mito. Lembremos que a mãe de Electra manda matar o pai da heroína. E é justamente neste ponto que o mito tem também a vantagem de trazer à tona a idealização do mundo masculino, já que Electra protege a figura paterna, apesar de seu pai ter sido ausente e cruel quando vivo. Por outro lado, o ódio pela mãe edípica, anteriormente amada, representa um ódio a si mesma, em função da via da identificação. A autora, ainda, comenta que Freud nem ao menos considerou a possibilidade do masoquismo feminino ser uma forma de autopunição pelo desejo de matar a mãe, dado o aspecto de identificação com a mesma.

No mito de Perséfone, proposto pelas americanas Kulish e Holtzman (1998), também a relação entre mãe e filha é enfocada. Mas neste, o ódio pela mãe e a consequente ambivalência da relação se mantêm inconscientes. As autoras defendem que o mito descreve uma situação de conflito triangular: há conflito na separação mãe-filha, mas não é da ordem de mãe-bebê, dado que há um terceiro, não um pai, mas alguém que se relaciona com a filha. Desta forma, a triangulação envolve a autorização da mãe para a mulher poder viver sua sexualidade genital, inscrevendo-a no mundo adulto. Sexualidade e agressividade, no mito de Perséfone, estão recalcadas e escondidas no submundo de Hades (esposo de Perséfone). A solução para o conflito triangular é uma formação de compromisso na qual a competição com a mãe fica absolutamente velada: só se sobressai a relação amorosa com a mãe, uma mãe que não permite o crescimento da filha. O mito traz, desta forma, a fantasia que muitas mulheres possuem de que, ao serem sexualmente ativas, perderiam o amor da mãe.

Finalmente, Birkested-Breen (1996) propõe uma conciliação entre as teorias kleiniana e lacaniana para o desenvolvimento psíquico da menina, com a diferenciação entre as palavras pênis e falo. Neste sentido, a autora seguiu o caminho da solução lacaniana que, de certa forma, permitiu a própria sobrevivência do mito de Édipo e do complexo de castração para o desenvolvimento psíquico da mulher. Lembremos que Lacan ao operar esta alteração - de pênis para falo - desloca o foco, no desenvolvimento psíquico da criança, do sexual, apoiado no corpo, para questões envolvendo poder na relação da criança com seus pais. Embora Lacan considere que retorna a Freud, deste ponto de vista ele parece se aproximar do Adler criticado por Freud no texto História do Movimento Psicanalítico de 1914. De qualquer forma, esta substituição aparentemente sutil parece realmente ter permitido a sobrevivência de pontos relevantes na psicanálise, como os citados anteriormente. BirkestedBreen, ao buscar conciliar Klein e Lacan, sugere a existência de duas posições no desenvolvimento da criança: a posição fálica e a posição penis-as-link. $\mathrm{Na}$ posição fálica, estaria em jogo a ilusão de completude e de independência em relação à necessidade. É um mundo habitado por dois: criança e mãe. Meninos e meninas vivenciariam esta fase de maneira distinta, já que os primeiros teriam a ilusão de possuir um falo. Mas a autora ressalta que o falo não existe, não é possessão de nenhum dos gêneros. A posição seguinte envolveria a triangulação, com a entrada do pai na relação dual. O nome penis-as-link tenta enfatizar o aspecto da ligação entre mãe e pai. Para que esta posição ocorra é preciso reconhecer a distinção anatômica, diferenças que podem se conectar. Porque, ao se reconhecer as diferenças, conhece-se a incompletude e a necessidade em relação ao objeto. Ao possibilitar a triangulação - não com o poderoso falo, mas com o pênis do pai que se liga à mãe e faz o corte na relação mãe-filha - a nova posição permite que o psiquismo ganhe tridimensionalidade, sendo, desta forma, estruturado. Este conceito foi usado por algumas autoras para compreensão de patologias que envolvem o uso do corpo como uma defesa. $\mathrm{Na}$ anorexia, a pessoa buscaria estruturação na concretude externa do corpo, que se aproxima da forma de um falo (pela rigidez de sua magreza), em razão da falha de estruturação no psiquismo.

\section{CONSIDERAÇÕES FINAIS}

Buscamos mostrar, no presente texto, uma análise comparativa entre os discursos psicanalíticos sobre a mulher influenciados pelo movimento feminista e após a consolidação do movimento na atualidade. $O$ discurso produzido no auge do feminismo, seguindo a tendência do movimento social, mostra uma necessidade de estabelecer a mulher como uma não negatividade e, assim, encontramos lá as mais intensas críticas às ideias freudianas. Uma maior consolidação do lugar da mulher na sociedade ocidental, conseguida com as influências que o movimento parece ter promovido ao longo das últimas décadas, é concomitante a alterações no discurso psicanalítico. 
Assim, encontramos, nos textos mais recentes, teorizações específicas relacionadas ao nascer mulher, o que a coloca em posição de positividade. Neste sentido, o homem deixou de ser a principal referência, bem como a lógica fálica deixou de ser imprescindível. Em seu lugar, encontramos multiplicidade no campo, uma multiplicidade que, em nossa análise, relaciona-se com a própria particularidade do órgão feminino.

\section{REFERÊNCIAS}

Bernstein, D. (1990). Female genial anxieties, conflict and typical mastery modes. International Journal of PsychoAnalysis, 71:151-165.

Birkested-Breen, D. (1996). Phallus, penis and mental space. The International Journal of Psycho-Analysis, 77(4), 649-657.

Freud, S. (1974). Sexualidade feminina. In Edição Standard Brasileira das Obras Psicológicas Completas de Sigmund Freud. (Vol. 21, pp. 255-279). Rio de Janeiro: Imago. (Trabalho original publicado em 1931).

Freud, S. (1975). Análise terminável e interminável. In Edição Standard Brasileira das Obras Psicológicas Completas de Sigmund Freud. (Vol. 23, pp. 284-287). Rio de Janeiro: Imago. (Trabalho original publicado em 1937).

Freud, S. (1975). Esboço de psicanálise: um exemplo de trabalho psicanalítico. In Edição Standard Brasileira das Obras Psicológicas Completas de Sigmund Freud. (Vol. 23, pp. 211223). Rio de Janeiro: Imago. (Trabalho original publicado em 1940 e escrito em 1938).

Freud, S. (1976). A dissolução do complexo de Édipo. In Edição Standard Brasileira das Obras Psicológicas Completas de Sigmund Freud (Vol. 19, pp. 215-224). Rio de Janeiro: Imago. (Trabalho original publicado em 1924).

Freud, S. (1976). Algumas consequências psíquicas da distinção anatômica entre os sexos. In Edição Standard Brasileira das Obras Psicológicas Completas de Sigmund Freud. (Vol. 19, pp. 301-320). Rio de Janeiro: Imago. (Trabalho original publicado em 1925).
Freud, S. (1976). Novas conferências introdutórias sobre psicanálise: feminilidade. In Edição Standard Brasileira das Obras Psicológicas Completas de Sigmund Freud. (Vol. 22, pp. 139165). Rio de Janeiro: Imago. (Trabalho original publicado em 1933 e escrito em 1932).

Freud, S. (1996). Estudos sobre a histeria. In Edição Standard Brasileira das Obras Psicológicas Completas de Sigmund Freud. (Vol. 2, pp. 13-318). Rio de Janeiro: Imago. (Trabalho original publicado em 1895).

Green, A. (1972). Aggression, femininity, paranoia and reality. International Journal of Psycho-Analysis, 53(2), 205-211.

Halberstadt-Freud, H. (1998). Electra versus Oedipus: Femininity reconsidered. International Journal of Psycho-Analysis, 79(1), 41-56.

Halberstadt-Freud, H. (2001). Electra cativa. Sobre a simbiose e a ilusão simbiótica entre mãe e filha e as consequências para o complexo de Édipo. Revista Brasileira de Psicanálise, 35(1), 143-168.

Kulish, N., \& Holtzman, D. (1998). Persephone, the loss of virginity and the female Oedipal complex. International Journal of Psycho-Analysis, 79(1), 57-71.

Laplanche, J., \& Pontalis, I. (2001). Vocabulário de Psicanálise (4a ed.). São Paulo: Martins Fontes.

Manhães, M. (1975). Psicologia da mulher. Revista Brasileira de Psicanálise, 9(4), 425-443.

Mitchel, J. (1979). Psicanálise e feminismo. Belo Horizonte: Interlivros.

Olesker, W. (1998). Female genital anxieties: views from the nursery to the couch. The Psychoanalytic Quarterly, 67(2), 276-294.

Senet, N. (2004). A study of preschool children's linking of genitals and gender. The Psychoanalytic Quarterly, 73(2), 291-334.

Stoller, R. J. (1968). The sense of femaleness. The Psychoanalytic Quarterly, 37(1), 42-55.

Volich, R. M. (1995). O eclipse do seio na teoria freudiana. Percurso, (14), 55-64.

Recebido em 21/08/2009

Aceito em 09/07/2010
Endereço para correspondência:

Gisele Cristiane Senne de Moraes. Rua Plínio de Morais, 307, CEP 01252-030, São Paulo-SP, Brasil.E-mail: gimoraes@uol.com.br. 